\title{
CADAVERIC STUDY OF ACCESSORY GROOVES ON LIVER IN WEST BENGAL POPULATION
}

\author{
Satabdi Sarkar *1, Banani Kundu ${ }^{2}$, Tanmay Sarkar ${ }^{3}$.
}

${ }^{{ }_{1}}$ Department of Anatomy, Murshidabad Medical College and Hospital, Berhampore, Murshidabad district, West Bengal, India.

${ }^{2}$ Department of Anatomy, R G Kar Medical College and Hospital, West Bengal, India.

${ }^{3}$ Department of Anaesthesiology, North Bengal Medical College and Hospital, West Bengal, India.

\section{ABSTRACT}

Background: Presence of accessory grooves on hepatic surface is not uncommon. Failure to appreciate such accessory grooves as anatomical variation may result in dilemma during imaging, surgery or autopsy. Literature pertaining to presence of accessory hepatic grooves is scarce and no such study was done on West Bengal population.

Materials and Methods: The researchers independently studied 63 wet specimens of liver during the period of three and half years in the department of Anatomy at various Medical Colleges of West Bengal.

Results: Approximately 6\% (6.34\%) of specimens had accessory grooves on different surfaces of liver.

Conclusions: Knowledge regarding the presence of accessory hepatic grooves may aid in better understanding of hepato-biliary pathologies during imaging, surgery and autopsy.

KEY WORDS: Hepatic Surfaces, Accessory Hepatic Grooves, Hepatic Grooves, Cadaveric Liver.

Address for Correspondence: Dr Satabdi Sarkar, 60/1, CC LANE, P.O. - Berhampore, District Murshidabad, West Bengal, India, 742101 E-Mail: dr.satabdi2010@gmail.com

\section{Access this Article online}

\section{Quick Response code}

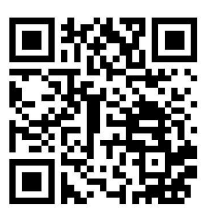

DOI: $10.16965 /$ ijar.2017.282
Web site: International Journal of Anatomy and Research

ISSN 2321-4287

www.ijmhr.org/ijar.htm

Received: 04 June 2017

Accepted: $18 \mathrm{Jul} 2017$

Peer Review: 04 June 2017

Revised: None
Published (O): 31 Aug 2017

Published (P): 31 Aug 2017

\section{INTRODUCTION}

Liver is the largest vital organ, occupying right hypochondrium and epigastric region, extending into left hypochondrium as far as left lateral line of the abdominal cavity. It is convex in the front, to the right, above, and behind; and is somewhat concave inferiorly, where it is moulded to the shapes of the adjacent viscera[1]. The liver is divided into a larger right and a much smaller left lobe by the line of attachment of the falciform ligament. In addition to the right and left lobes, the porta hepatis divides the liver into two additional lobes, a quadrate lobe in the front and the caudate lobe behind.

Studies on the variations in ductal and vascular anatomy of the liver are common, But literature pertaining to presence of grooves on hepatic surface is very scarce [2-6].

Accessory grooves are prominent vertical depression that appear on the hepatic surfaces. There is no unanimous nomenclature since various researchers used different names including accessory fissures [2], hepatic fissures [3], diaphragmatic sulci [4], hepatic furrows[5] 
and accessory sulci [6].

Proper knowledge of normal and variant liver is a prerequisite for safe surgical and diagnostic approach. These type of morphological variations of liver has not been previously reported in West Bengal population. So we studied the presence of accessory grooves in this population to provide important information regarding the liver and billiary system in the era of rapid progression/ advance in hepatobilliary sciences.

\section{MATERIALS AND METHODS}

63 formalin fixed specimens of liver were examined, over a period of three and half years in the department of Anatomy at various Medical Colleges of West Bengal. Among these, 29 specimens had been removed from adult human cadavers during routine dissection for undergraduate and postgraduate medical teaching, between 2013 to 2016 and then preserved in $10 \%$ formalin solution. Rest of the specimens were obtained from wet museum.

Each surface of liver that is anterior, superior, posterior, right lateral and inferior was studied in detail for the presence of accessory fissures. When any accessory fissures were noticed during dissection, an in- situ relationship to nearby organs including ribs and diaphragmatic slips was thoroughly performed to exclude indentation or impression marks. The number and location of all such accessory fissures were recorded.

\section{RESULTS}

Morphometric Data: The weight of livers ranged from 800 to 2200 grams. The height and width ranged from $7.5-25 \mathrm{~cm}$ and $10.4-21 \mathrm{~cm}$ respectively.

Morphological Aspects: In present study we got 59 formalin fixed specimens of liver which had no accessory fissures on the surfaces. Remaining 4 specimens appeared normal but they had accessory fissures on different surfaces of liver. Out of these four, two specimens had accessory fissures on the anterosuperior surface, one had on the inferior surface and the fourth one had fissures on both the antero-superior and inferior surface. The length and depth of the fissures present on the antero-superior surface appeared to be more than the fissures of the inferior surface.

Fig. 1: Showing accessory groove on antero-superior surface of liver.

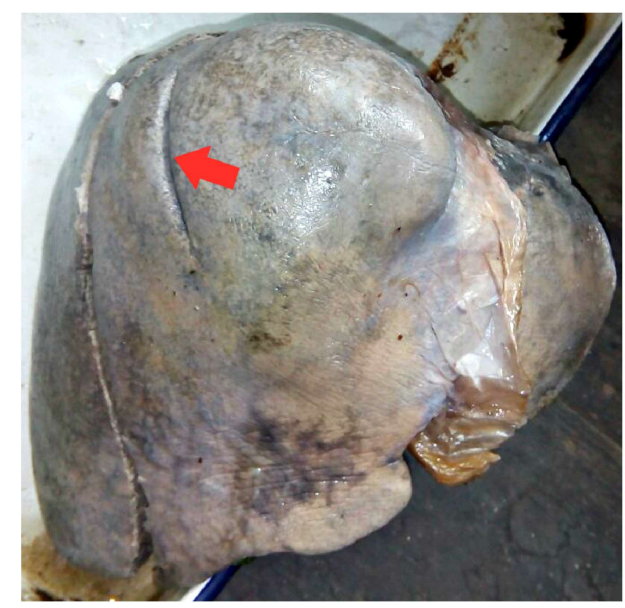

Fig. 2: Showing accessory groove on antero-superior surface of liver.

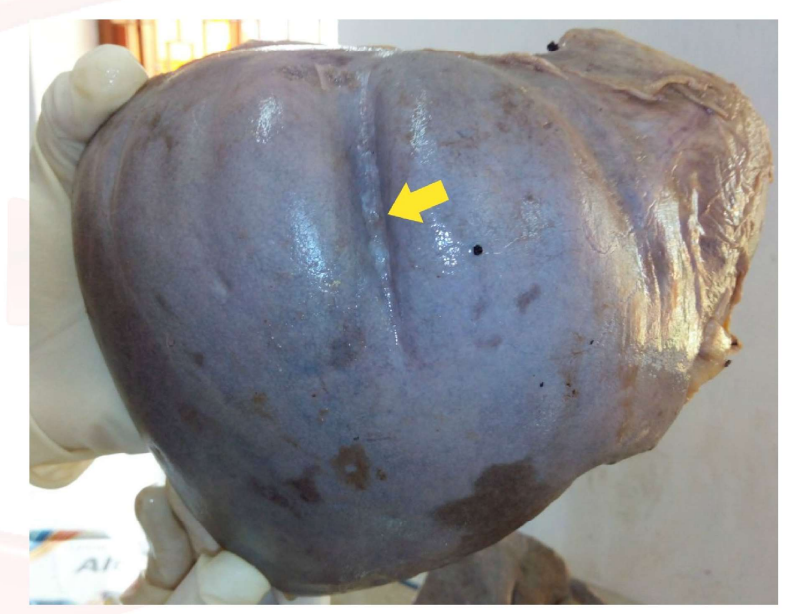

Fig. 3: Showing accessory grooves on inferior surface of liver.

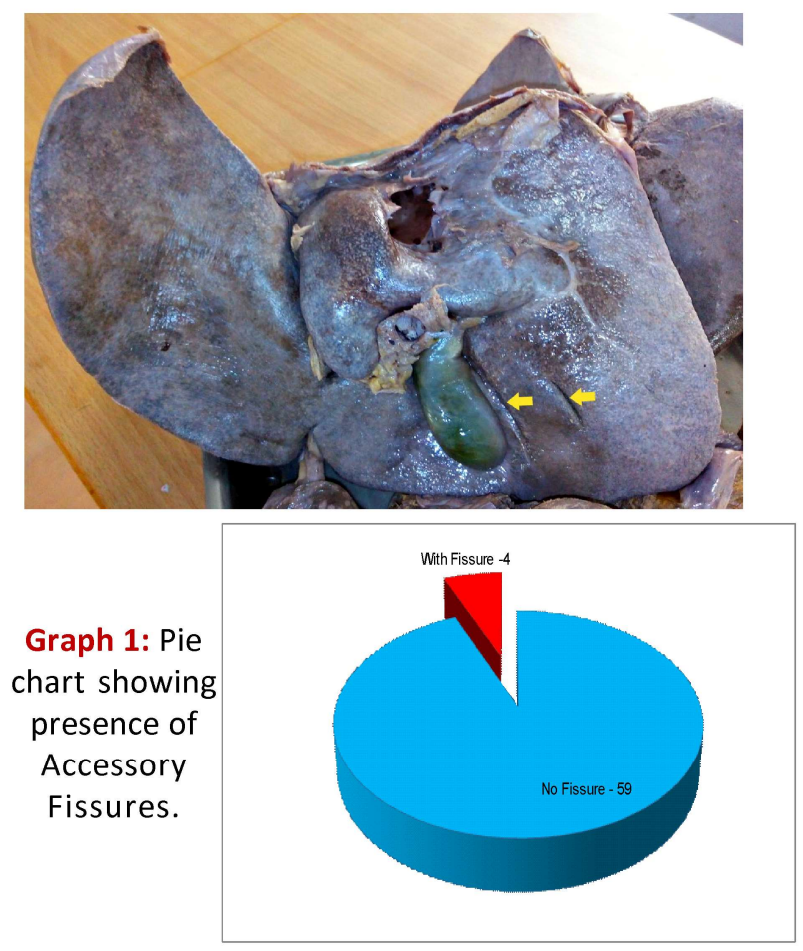


Graph 2: Bar Diagram Showing Accessory fissures on different surfaces.

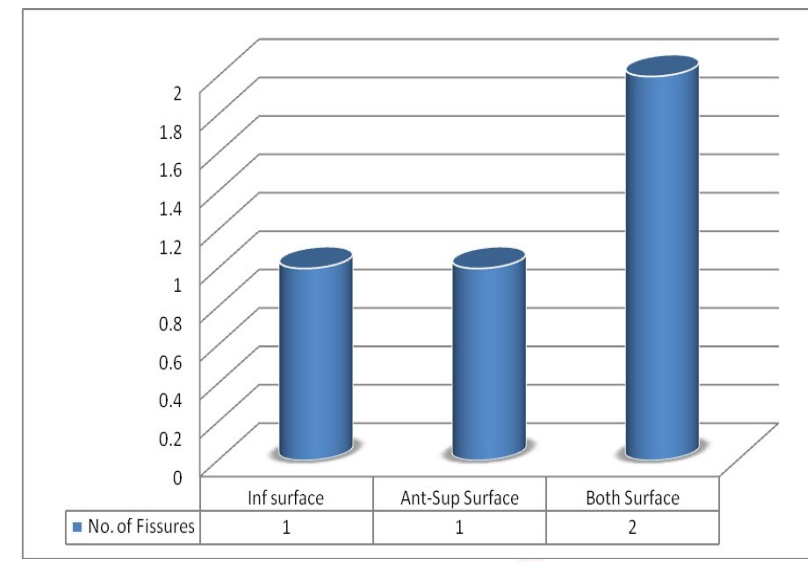

\section{DISCUSSION}

Falciform ligament is attached to the anterior surface of the liver and merged to the right and left superior coronary ligament [7].

The liver is known to have accessory fissures. In this age of advanced imaging, it becomes very important for a clinician, surgeon, radiologist and autopsy surgeons to have a thorough knowledge of anatomy and commonly occurring variations in liver. There were variations in the surface anatomy in $12 \%$ of randomly selected cadaveric livers [8]. The knowledge of accessory grooves gradually becomes important as cross sectional imaging of abdomen is now an essential part of modern medicine practice specially in the field of hepatobilliary services. Their presence may lead to dilemma or false positive diagnosis, as they may resemble pathological liver diseases ${ }^{2}$ and traumatic liver injury [6]. On ultrasonography multiple accessory fissures also may be confused with a macronodular liver,so a supplementary CT scan is often helpful for further confirmation.

The accessory fissures may be confused with normal sulci during partial hepatectomy [9]. They may also increase the complexity in the liver transplantation by hepato-billiary surgeons [10]. The prevalence of HSG in this Afro-Caribbean population is comparable with that in published series, ranging from $5 \%$ in Malaysia [6], 6\% in India [11], 25\% in New York, $\mathrm{USA}^{2}$ to $40 \%$ in Italy [4]. The majority of HSGs occurred at the antero-superior surface near the midline.

Joshi etal reported notching along the infe- rior border of caudate lobe in $18 \%$ of livers, vertical fissure in $30 \%$ and prominent papillary process in $32 \%$ of livers in their extensive study on lobes and fissures [11].

Hepatic development is usually discussed under three phases. In Competence phase the hepatic diverticulum appears on the $18^{\text {th }}$ day of gestation as a thickening of the ventral wall of the distal foregut endoderm. Next is the Specification phase. There specification of the liver gene program within the entoderm occurs by signals from the cardiac mesoderm. In Morphogenesis phase the growth of the hepatic bud in the septum transversum mesenchyme takes place. And finally the liver is formed by the integration of the parenchymal cells. The causes of anomalies in hepatic morphology that occurs during any of these three phases of organogenesis, is yet to be properly explained. Awareness regarding such anomalies will help to decrease morbidity.

Knowledge regarding atrophy, agenesis, and presence of accessory fissures or lobes may reduce diagnostic errors in interpretation for radiologists, surgeons and anatomists. Awareness helps to avoid fatal or serious complications and assists in planning appropriate surgical approaches. Hence this work was conducted to emphasize awareness among clinicians and embryologists, regarding presence of such morphological variations in liver.

\section{ABBREVIATIONS}

HSG - Hepatic Surface Grooves

\section{ACKNOWLEDGEMENTS}

Department of Anatomy Murshidabad Medical College, Department of Anatomy R.G. Kar medical College Kolkata, Department of Anaesthesia North Bengal Medical College and other Medical Colleges of West Bengal.

\section{Conflicts of Interests: None}

\section{REFERENCES}

[1]. S. Gray's Anatomy: The Anatomical Basis of Clinical Practice 40th ed. New York: Churchill Livingstone 2008;3441-46.

[2]. Auh Y.H., Rubenstein W.A., Zirinsky K., Kneeland J.B., Pardes J.C., Engel I.A., Whalen J.P., Kazam E. Accessory fissures of the liver: CT and sonographic appearance. Am. J. Roentgenol. 1984;3:565-572. 
[3]. Lim J.H., Tae Ko Y., Han M.C., Kim C.W., Choi B.I., Im J.G. The inferior accessory hepatic fissure: sonographic appearance. Am J Roentgenol. 1987;149:495-497.

[4]. Macchi V., Feltrin G., Parenti A., De Caro R. Diaphragmatic sulci and portal fissures. J. Anat. 2003;202:303-308.

[5]. Newell R.L.M., Morgan-Jones R. Grooves in the superior surface of the liver.Clin. Anat. 1993;6:333-336.

[6]. Othman F.B., Latiff A.A., Suhaimi F.H., Das S. Accessory sulci of the liver: An anatomical study with clinical implications. Saudi Med. J. 2008;29:12471249.

[7]. Sibulesky L. Normal liver anatomy. Clin. Liver Dis. 2013;2:1-3.

[8]. Michael T, Gardner ,Shamir O, Cawich, Ramanand Shetty, Neil W. Pearce, Vijay Narayn Singh H(2015) Hepatic surface grooves in an Afro-Caribbean population: a cadaver study. Italian Journal of Anatomy and Embryology. 2015;120(2):117-126.
[9]. Johnson P.B., Shah S., Roberts P., Arthurs M., Murphy T., Bonadie K.O., Crandon I.W., Harding H.E., AbuHilal M., Pearce N.W. The multidisciplinary team approach to hepatobiliary diseases: a working model in the Caribbean setting. J. Multidisciplinary Healthcare 2014;7:1-4.

[10]. Alonso-Torres A., Fernandez-Cuadrado J., Pinilla I., Parron M., de Vicente E., LopezSantamaria M. Multidetector CT in the evaluation of potential living donors for liver transplantation. Radiographics 2005;25:1017-1030.

[11]. Joshi S.D., Joshi S.S., Athavale S.A. Some interesting observations on the surface features of the liver and their clinical implications. Singapore Med. J. 2009;50:715-719.

How to cite this article:

Satabdi Sarkar, Banani Kundu, Tanmay Sarkar. CADAVERIC STUDY OF ACCESSORY GROOVES ON LIVER IN WEST BENGAL POPULATION. Int J Anat Res 2017;5(3.2):4191-4194. DOI: 10.16965/ijar.2017.282 